\title{
Functionalization of the Fine $\mathrm{Al}_{2} \mathrm{O}_{3}$ Abrasive by the Polyacrylamide Deposition
}

\author{
Pengfei MA ${ }^{1}$, Xiao XIAO $^{1}$, Yuxin GAO $^{1}$, Wen YANG $^{1}$, Baojun $^{\text {CHENG }}{ }^{1}$, Ping ZHANG $^{2}$ \\ ${ }^{1}$ China Construction West Building Materials Science Research Institute, Chengdu 610064, China \\ ${ }^{2}$ School of Materials Science and Engineering, Sichuan University, Chengdu 610064, China \\ crossref http://dx.doi.org/10.5755/j02.ms.24476
}

Received 21 October 2019; accepted 05 February 2020

\begin{abstract}
In order to enhance the dispersion stability of ultra-fine $\mathrm{Al}_{2} \mathrm{O}_{3}$ powder in aqueous media, the alumina particles were modified with silane coupling agent KH570 at first, and then 2,2'-Azobis(2-amidinopropane) dihydrochloride (AIBA) was anchored onto the modified $\mathrm{Al}_{2} \mathrm{O}_{3}$ to initiate the graft polymerization of acrylamide monomer (AM), and $\mathrm{PAM} / \mathrm{Al}_{2} \mathrm{O}_{3}$ composite particles were obtained finally. The structure and dispersion property of $\mathrm{Al}_{2} \mathrm{O}_{3}$ composite particles were characterized by XPS, FTIR, laser particle size analyzer, micro electrophoresis apparatus, SEM and spectrophotometer. The results indicated that the attained composite abrasive when water-soluble azo initiator was added at $40{ }^{\circ} \mathrm{C}$ showed good dispersion stability in aqueous media with $\mathrm{PAM}$ as shell and $\mathrm{Al}_{2} \mathrm{O}_{3}$ as core. Compared with unmodified $\mathrm{Al}_{2} \mathrm{O}_{3}$, the reunion phenomenon of grafting polymerization modified $\mathrm{Al}_{2} \mathrm{O}_{3}$ powder was improved by $\mathrm{AM}$, the D50 of the modified particles reduced. The isoelectric point (IEP) of the grafting modified particles migrated, and the zeta potential of the modified particles reached to the maximum value when the $\mathrm{pH}$ was 9 . After $\mathrm{PAM} / \mathrm{Al}_{2} \mathrm{O}_{3}$ abrasive polished, the surface roughness of $\mathrm{NiP} / \mathrm{Al}$ hard disk surface was obviously reduced.

Keywords: $\mathrm{Al}_{2} \mathrm{O}_{3}$ ultrafine powder, azo initiator, dispersion, surface modification, composite abrasive.
\end{abstract}

\section{INTRODUCTION}

With the rapid development of social progress and sophisticated technology, the surface quality requirements of electronic products continue to increase, and surface flattening technology is also constantly developing. Chemical mechanical polishing (CMP) is widely applied in high-precision planarization of surface parts of advanced electronic products such as integrated circuits and computer hard disks [1-2]. One of the keys to CMP technology is the preparation of abrasives and the dispersion stability of polishing fluids, which directly affect the polishing rate, selectivity and damage to the surface of the substrate [3-4].

As an abrasive used widely, $\mathrm{Al}_{2} \mathrm{O}_{3}$ has the disadvantages of poor dispersion stability and easy agglomeration in the process of formulating slurry. The surface of $\mathrm{Al}_{2} \mathrm{O}_{3}$ was modified by chemical method $\square$ in general [5]. The modification methods include surface chemical coating modification method, physical modification method, mechanical modification method, etc. [6]. At present, the surface chemical coating modification method is used [7]. Since the organic matter is difficult to coat directly on the surface of the $\mathrm{Al}_{2} \mathrm{O}_{3}$ powder, even if it is coated, most of it is physically adsorbed, and the bonding is unstable. However, the hydroxyl group on the surface of $\mathrm{Al}_{2} \mathrm{O}_{3}$ powder is easy to react with the alkoxy group, and the silane coupling agent $\left(\mathrm{CH}_{2}=\mathrm{C}\left(\mathrm{CH}_{3}\right) \mathrm{COOC}_{3} \mathrm{H}_{6} \mathrm{Si}\left(\mathrm{OCH}_{3}\right)_{3}\right.$, abbreviated as $\mathrm{KH} 570$ ) is selected as the intermediate transition layer [8], which can set up a "molecular bridge" between the interfaces of the inorganic materials and organic materials, connecting two materials with different properties together.

\footnotetext{
* Corresponding author. Tel.: +86-18328061278.

E-mail address: 441016802@qq.com (B. Cheng)
}

Therefore, the outer layer selects acrylamide $\left(\mathrm{CH}_{2}=\mathrm{CHCONH}_{2}, \mathrm{AM}\right)$ to form water-soluble molecular polyacrylamide $\left(\left[-\mathrm{CH}_{2}-\mathrm{CH}\left(\mathrm{CONH}_{2}\right)\right]_{\mathrm{n}}\right)$, referred to as PAM) through the polymerization reaction, which can improve the hydrophilicity of $\mathrm{Al}_{2} \mathrm{O}_{3}$ particles [9].

The surface of the $\mathrm{Al}_{2} \mathrm{O}_{3}$ particles is anchored with an azo initiator to reduce the polymerization temperature and increase the conversion rate of the polymerization reaction [10]. In recent years, water-soluble azo-initiated systems have been greatly developed and highly applied [11], since peroxides such as potassium persulfate and ammonium persulfate must initiate polymerization at higher temperatures [12]. However, AIBA is a water-soluble azo initiator with lower activation energy, which can initiate polymerization at a low temperature and low concentration. And its polymerization has the advantage of reaction fast, high degree of completion and constant $\mathrm{pH}$. In addition, AIBA can produce polymers with ultra-high molecular mass and high water solubility [13], which can effectively increase the decomposition rate of free radicals on the surface of $\mathrm{Al}_{2} \mathrm{O}_{3}$ particles and produce more surface-active sites [14].

In this paper, the polyacrylamide $\mathrm{PAM} / \mathrm{Al}_{2} \mathrm{O}_{3}$ composite particles were synthesised by anchoring the azo initiator on the surface of $\mathrm{Al}_{2} \mathrm{O}_{3}$ particles to initiate the polymerization of acrylamide. The dispersion stability of $\mathrm{Al}_{2} \mathrm{O}_{3}$ particles in aqueous medium was improved, and the dispersion of particles and dispersion stability in aqueous medium was analysed.

\section{EXPERIMENTAL}

$\mathrm{Al}_{2} \mathrm{O}_{3} \quad$ ultrafine powder: $\mathrm{D} 50=1.930 \mu \mathrm{m}, \quad \mathrm{Al}_{2} \mathrm{O}_{3}$ content is $99.99 \%$ (mass fraction, the same below), Zhejiang Superfine Chemical Co., Ltd.; silane coupling agent (KH570, analytical grade, Nanjing Xinhuai 
Technology Co., Ltd.); acrylamide (analytically pure, 99.0 \%, produced by Chengdu Kelong Chemical Reagent Factory); Azobisisobutylphosphonium hydrochloride (analytical grade, 98.0\%, produced by Nanjing Dulai Biotechnology Co., Ltd.); Anhydrous ethanol (analytically pure, 99.7\%, Chengdu Changzheng Chemical Reagent Factory); Nitrogen (99.99\%, produced by Chengdu Xuri Chemical Co., Ltd.).

$10 \mathrm{~g}$ of $\mathrm{Al}_{2} \mathrm{O}_{3}$ was dispersed in $200 \mathrm{ml}$ of absolute ethanol, and ultrasonicated in an ultrasonic machine for $30 \mathrm{~min}$; $5.0 \mathrm{~g}$ of a silane coupling agent was added to a $500 \mathrm{ml}$ three-necked flask and uniformly mixed with an anhydrous ethanol solution of $\mathrm{Al}_{2} \mathrm{O}_{3}$. The mixture, firstly, was heated to $80{ }^{\circ} \mathrm{C}$ in a magnetic stirring water bath, then refluxed for $5 \mathrm{~h}$ and centrifuged to remove ethanol from the $\mathrm{Al}_{2} \mathrm{O}_{3}$ powder. The mixture, finally, was washed 6 times with absolute ethanol and dried under vacuum at $80{ }^{\circ} \mathrm{C}$ for $12 \mathrm{~h} .5 \mathrm{~g}$ of $\mathrm{Al}_{2} \mathrm{O}_{3}$ modified with $\mathrm{KH} 570$ was dispersed in $100 \mathrm{ml}$ of distilled water, stir for $30 \mathrm{~min}$, vacuum and fill with nitrogen for 5 times, $0.025 \mathrm{~g}$ of azo initiator was added in a three-necked flask, heated up to $40{ }^{\circ} \mathrm{C}$, and reacted for $25 \mathrm{~min}$. The three-necked flask was opened and $5 \mathrm{~g}$ of acrylamide monomer was added in one time. After magnetic stirring for $4 \mathrm{~h}$, it was naturally cooled to room temperature under a nitrogen atmosphere.

In polishing the experiment, a self-made polishing solution was used, and the computer NiP/Al hard disk substrate was polished with a M480 flat polishing machine. The polished workpiece was a $\Phi 95 \mathrm{~mm}$ NiP/Al hard disk substrate. The polished disc substrate was washed in a cleaning solution containing a surfactant, and measured after drying. Surface roughness ( $\mathrm{Ra}$ ) and morphology were characterized with a SPA400 atomic force microscope (AFM) from Seiko Corporation.

The phase composition and morphology of samples was analyzed by scanning electron microscopy (SEM, HITACHI TM-1000). The content and binding energy were investigated by X-ray photoelectron spectroscopy (XPS, EscaLab 250Xi). The zeta potentials of the samples with variation of $\mathrm{pH}$ were measured by zetasizer nano (Malvern Instrument). The chemical structure of the samples was characterized by a Fourier infrared spectrometer (FT-IR, Nicolet 6700). The particle size distribution of samples in ultrapure water was analyzed by a laser particle size meter (Rise-2008, China). The light transmittance of suspension was investigated by spectrophotometer (752N, China).

\section{RESULTS AND DISCUSSION}

\subsection{XPS analysis}

Fig. 1 shows the XPS spectra of pure $\mathrm{Al}_{2} \mathrm{O}_{3}$ and modified $\mathrm{Al}_{2} \mathrm{O}_{3}$ powders, respectively. It can be seen from the comparison of Fig. $1 \mathrm{a}$ and Fig. $1 \mathrm{~b}$ that the intensity of Cls is obviously enhanced. Since XPS measurement range is surface atomic layer with thickness $\leq 10 \mathrm{~nm}$, this is mainly the contribution of acrylamide to carbon. Moreover, the XPS spectrum before and after the modification can also be found that the peak of $\mathrm{N}$ appears on the surface after modification, and the binding energy of Nls is $404.1 \mathrm{eV}$, which corresponds to $\mathrm{N}$ in acrylamide.
This indicates that acrylamide has been successfully grafted onto the surface of $\mathrm{Al}_{2} \mathrm{O}_{3}$.

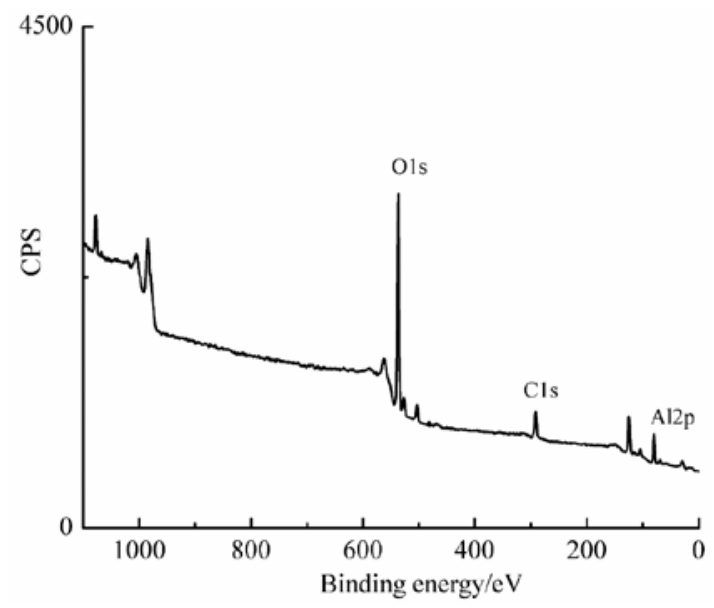

a

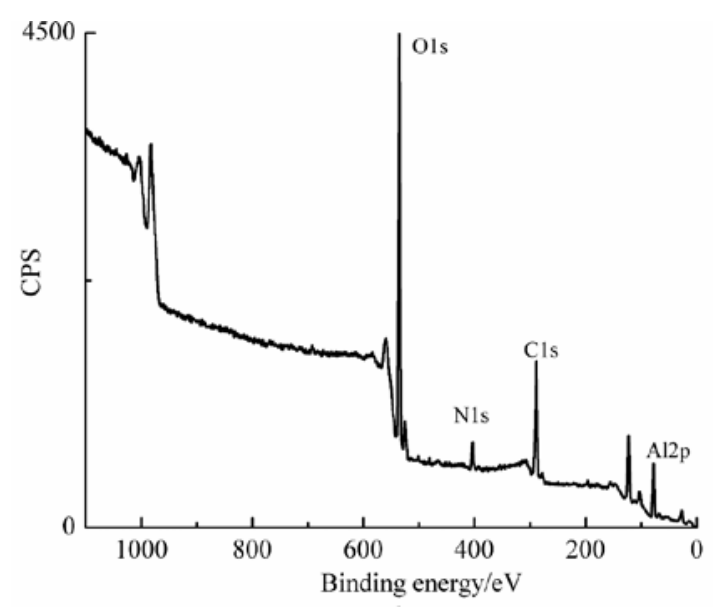

b

Fig. 1. XPS survey spectra of $\mathrm{Al}_{2} \mathrm{O}_{3}$ powders: a-before modification; $\mathrm{b}$-after modification

\subsection{FT-IR analysis}

It can be seen from Fig. 2 and Fig. 3 that before and after the modification, there is a $-\mathrm{OH}$ stretching vibration peak near $3437.21 \mathrm{~cm}^{-1}$; $\mathrm{Al}-\mathrm{O}$ is between $1000 \mathrm{~cm}^{-1}$ and $500 \mathrm{~cm}^{-1}$.

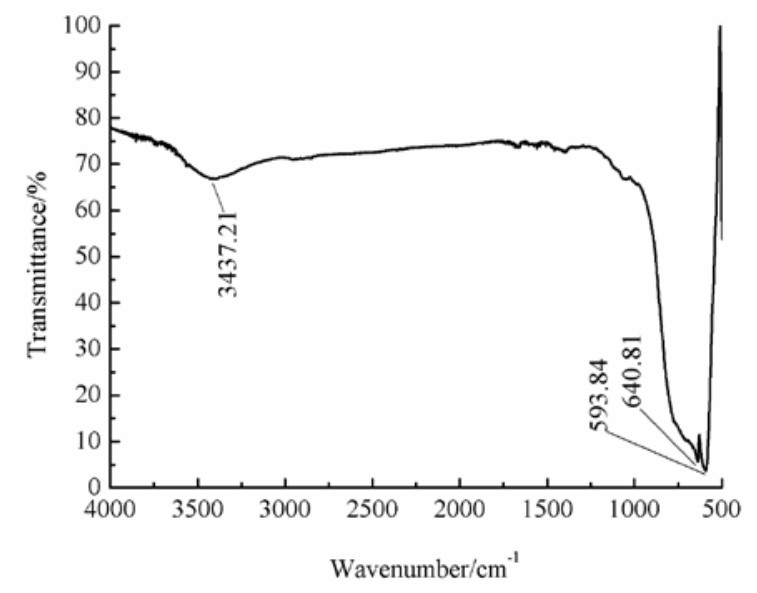

Fig. 2. FT-IR spectra of raw $\mathrm{Al}_{2} \mathrm{O}_{3}$ powders. 
The KH570 ester-modified $\mathrm{Al}_{2} \mathrm{O}_{3}$ showed a $\mathrm{C}=\mathrm{O}$ absorption peak in the KH570 ester group at $1643.85 \mathrm{~cm}^{-1}$, and a methyl stretching vibration peak appeared at $2921.63 \mathrm{~cm}^{-1}$ and $2857.99 \mathrm{~cm}^{-1}$. At the same time, a new absorption peak appeared at $1400.09 \mathrm{~cm}^{-1}$. Fig. 3 a shows that the newly emerging absorption peak in the infrared spectrum is formed by the characteristic peak of the functional group corresponding to $\mathrm{KH} 570$, indicating that $\mathrm{KH} 570$ has been coupled to the surface of $\mathrm{Al}_{2} \mathrm{O}_{3}$ by chemical bonding.

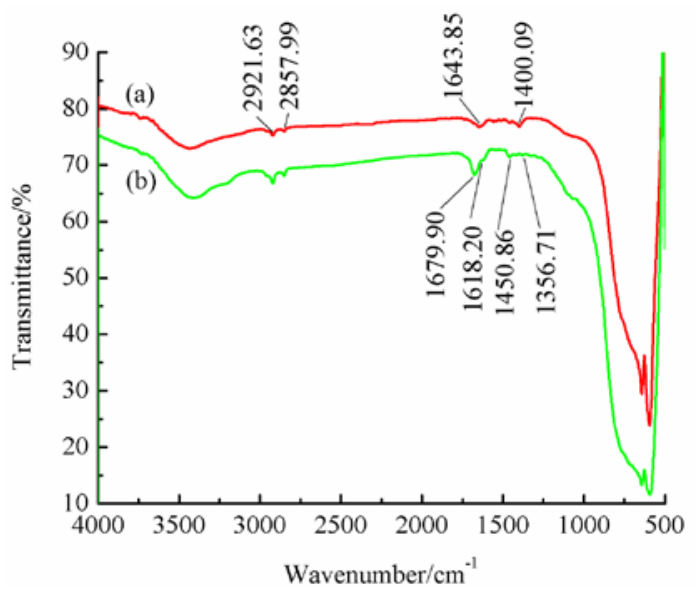

Fig. 3. a-FT-IR spectra of $\mathrm{Al}_{2} \mathrm{O}_{3}$ powders modified with KH570; b-FT-IR spectra of $\mathrm{Al}_{2} \mathrm{O}_{3}$ powders with grafting $\mathrm{AM}$

According to the literature [15], in the characteristic absorption band of amide, the $\mathrm{NH}_{2}$ absorption band is located near $1620 \mathrm{~cm}^{-1}$, and the $\mathrm{NH}_{2}$ absorption band appears at $1618.20 \mathrm{~cm}^{-1}$ of Fig. $3 \mathrm{~b}$. And the hydroxyl absorption peak of the amide appeared at $1679.90 \mathrm{~cm}^{-1}$, the $\mathrm{C}=\mathrm{C}$ stretching vibration peak in the acrylamide monomer was around $1640 \mathrm{~cm}^{-1}$, and there was no such peak in the polyacrylamide, only the carbonyl group of about $1680 \mathrm{~cm}^{-1}$. The absorption peak indicates that the acrylamide monomer forms a polyacrylamide by reaction. At the same time, there are several new absorption peaks between $1500 \mathrm{~cm}^{-1}$ and $1000 \mathrm{~cm}^{-1}$, and the $\mathrm{C}-\mathrm{N}$ or $\mathrm{C}-\mathrm{C}$ bond stretching vibration peaks connected to $\mathrm{C}=\mathrm{O}$ appear at $1450.86 \mathrm{~cm}^{-1}$ and $1356.71 \mathrm{~cm}^{-1}$, respectively. The analysis indicated that the acrylamide monomer-initiated polymerization on the surface of the inorganic particles by the "molecular bridge" action of KH570, which had been graft polymerized onto the surface of the modified $\mathrm{Al}_{2} \mathrm{O}_{3}$.

\subsection{SEM analysis}

The dispersion of pure $\mathrm{Al}_{2} \mathrm{O}_{3}$ and modified $\mathrm{Al}_{2} \mathrm{O}_{3}$ powder in water was observed by US FEI environmental scanning electron microscope, as shown in Fig. 4. It can be seen that the dispersibility of the modified $\mathrm{Al}_{2} \mathrm{O}_{3}$ is greatly improved compared with the pure $\mathrm{Al}_{2} \mathrm{O}_{3}$. The pure $\mathrm{Al}_{2} \mathrm{O}_{3}$ particles adsorbed to each other, and the agglomeration was serious. The large particles and fine particles formed a large agglomerate; while the modified $\mathrm{Al}_{2} \mathrm{O}_{3}$ fine particles increased significantly, and the surface agglomeration of the particles was significantly decreased. This is due to the grafting of $\mathrm{KH} 570$-modified polyacrylamide on the surface of $\mathrm{Al}_{2} \mathrm{O}_{3}$. On the one hand, the surface energy of $\mathrm{Al}_{2} \mathrm{O}_{3}$ particles is reduced after grafting the acrylamide monomer, and the polyacrylamide chain grafted on the surface of $\mathrm{Al}_{2} \mathrm{O}_{3}$ is in the water.
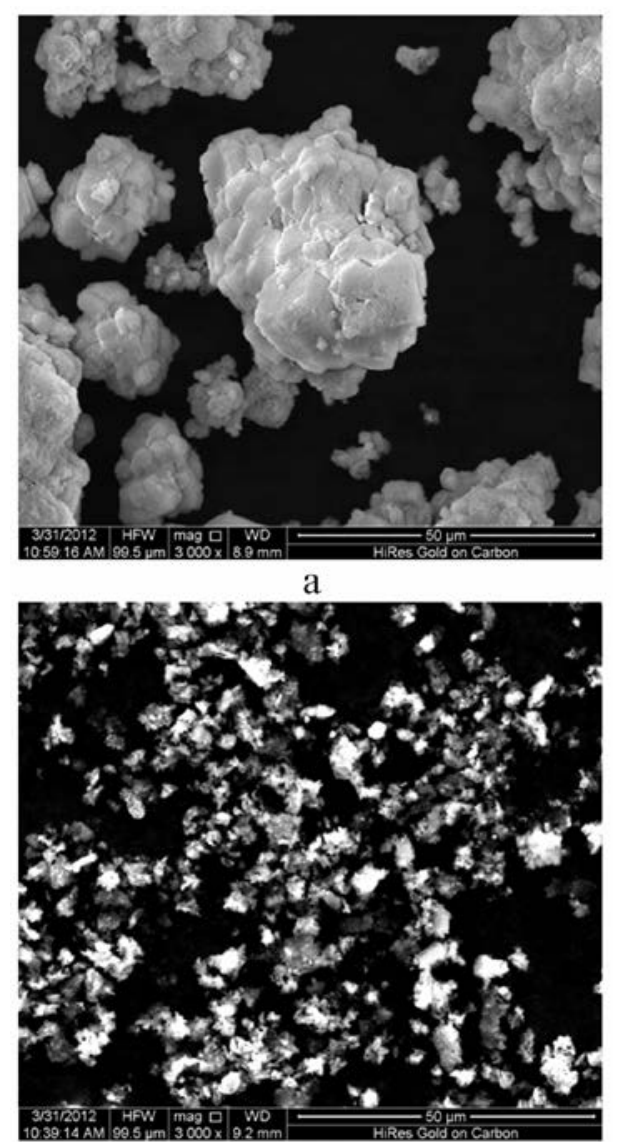

b

Fig. 4. SEM images of $\mathrm{Al}_{2} \mathrm{O}_{3}$ powders: a -before modification; $\mathrm{b}$-after modification

Stretching out, a certain thickness of the steric layer can be formed on the surface of $\mathrm{Al}_{2} \mathrm{O}_{3}$ to achieve the effect of the steric barrier (position resistance), and the surface agglomeration of the $\mathrm{Al}_{2} \mathrm{O}_{3}$ particles is prevented by the resistance of the position repulsive force.

\subsection{Particle size analysis}

The pure $\mathrm{Al}_{2} \mathrm{O}_{3}$ powder and the modified $\mathrm{Al}_{2} \mathrm{O}_{3}$ powder were prepared into a dilute solution, respectively, and after ultrasonic dispersion, the particle size and distribution of the $\mathrm{Al}_{2} \mathrm{O}_{3}$ powder before and after the modification were measured by a laser particle size analyzer. The results are shown in Fig. 5. It can be seen from Fig. 5 and Table. 1 that after the surface modification of the pure $\mathrm{Al}_{2} \mathrm{O}_{3}$ powder, the median particle size D50 is significantly reduced, which is due to the improvement of the surface agglomeration phenomenon of the powder and the improvement of the dispersibility in the aqueous medium.

\subsection{Zeta potential analysis}

The type of charge carried on the surface of the particle and the charge density on the surface of the particle can be reflected from the zeta potential value, which can usually be used to judge the dispersion stability of the ultrafine powder in an aqueous medium. The zeta 
potential curves of pure $\mathrm{Al}_{2} \mathrm{O}_{3}$ and graft modified $\mathrm{Al}_{2} \mathrm{O}_{3}$ are shown in Fig. 6.

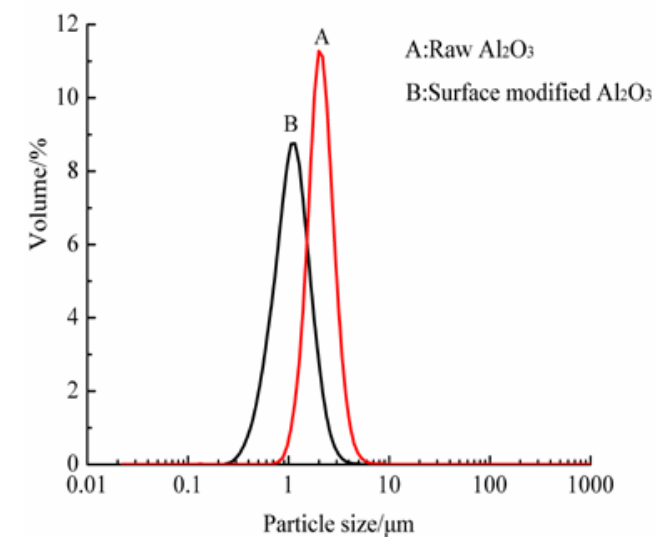

Fig. 5. Particle size distribution of $\mathrm{Al}_{2} \mathrm{O}_{3}$ powders before and after modification

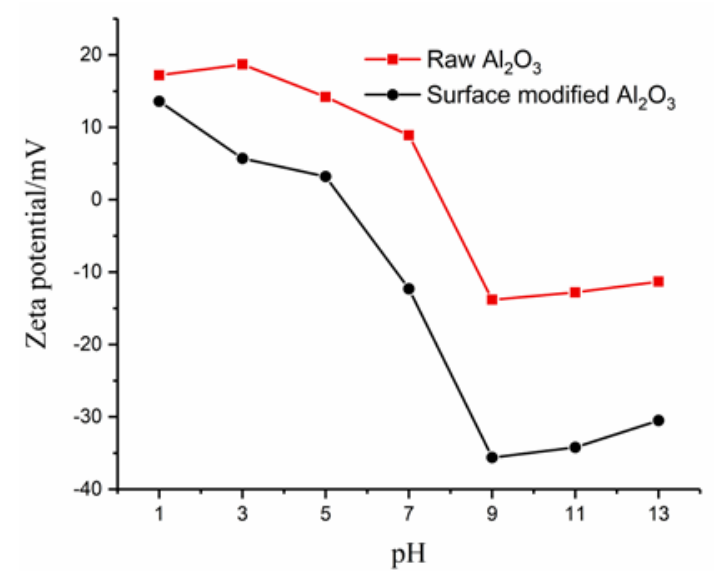

Fig. 6. Zeta potential curves of $\mathrm{Al}_{2} \mathrm{O}_{3}$ powders before and after modification

It can be seen that the electrical properties of the coated $\mathrm{Al}_{2} \mathrm{O}_{3}$ particles after grafting with polyacrylamide have changed. The isoelectric point (IEP) of pure $\mathrm{Al}_{2} \mathrm{O}_{3}$ is near $\mathrm{pH}=8.0$, and the absolute value of the maximum potential is about $18.7 \mathrm{mv}(\mathrm{pH}=3)$. The IEP of modified $\mathrm{Al}_{2} \mathrm{O}_{3}$ moves from alkaline to acidic, and the IEP is located near $\mathrm{pH}=5.7$, and the absolute value of the maximum potential is $35.6 \mathrm{mV}(\mathrm{pH}=9)$. The charge properties of the surface of $\mathrm{Al}_{2} \mathrm{O}_{3}$ particles are related to the properties of polyacrylamide, and the negative charge increases, and the IEP moves toward alkalinity. And under alkaline conditions, the modified $\mathrm{Al}_{2} \mathrm{O}_{3}$ exhibits a higher absolute value of the zeta potential than pure $\mathrm{Al}_{2} \mathrm{O}_{3}$.

Studies have shown that under the action of the initiator, the $\mathrm{C}=\mathrm{C}$ double bond of the acrylamide monomer is opened and grafted with the tail end of the coupling agent on the surface of the powder to form a certain spatial structure. The polyacrylamide organic coating has a certain spatial structure and hydrolysis activity, and can be converted into a carboxyl group-containing polymer by hydrolysis of its amide group. The hydrolysis reaction mechanism is as shown in Fig. 7.

The hydrolysate with a carboxylic acid group structure is an important anionic polyelectrolyte, so the relationship between the zeta potential and the $\mathrm{pH}$ of the double-coated $\mathrm{Al}_{2} \mathrm{O}_{3}$ suspension solution is the same as that of the ceramic powder adsorbing the anionic polyelectrolyte [16].

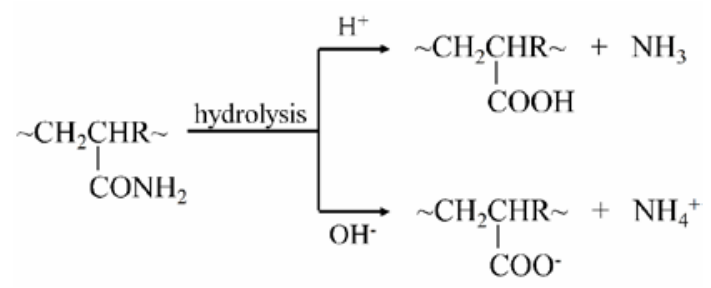

Fig. 7. The schematic diagram of hydrolysis reaction mechanism

The carboxylic acid group of the hydrolyzed polyacrylamide is either present as $-\mathrm{COOH}$ or dissociated to - $\mathrm{COO}-$, and the fraction of the dissociated $-\mathrm{COOH}$ group is closely related to the $\mathrm{pH}$ of the solution. When the solution is strongly acidic, - $\mathrm{COOH}$ hardly dissociates; when the solution is alkaline, $-\mathrm{COOH}$ is completely dissociated. As the degree of $-\mathrm{COOH}$ dissociation increases, the surface charge properties of the polymer change from neutral to very high electronegativity. This fully confirms that the polyacrylamide has been successfully grafted onto the surface of the $\mathrm{Al}_{2} \mathrm{O}_{3}$ powder.

\subsection{Dispersion stability analysis}

According to the change of light transmittance, the dispersion stability of $\mathrm{Al}_{2} \mathrm{O}_{3}$ in aqueous medium can be reflected. The light transmittance of the $\mathrm{Al}_{2} \mathrm{O}_{3}$ powder suspension before and after the modification was measured, as shown in Fig. 8. The transmittance of pure $\mathrm{Al}_{2} \mathrm{O}_{3}$ suspension increased rapidly as time goes by. Light transmittance reached $78 \%$ or more only 3 days and reached over $90 \%$ after 7 days, indicating that the dispersion stability of pure $\mathrm{Al}_{2} \mathrm{O}_{3}$ suspension was poor, 7 days almost complete settling.

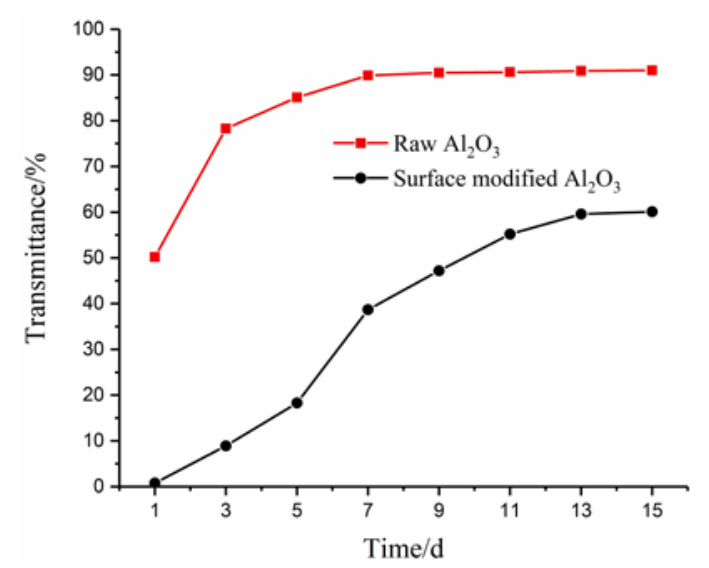

Fig. 8. Stability of $\mathrm{Al}_{2} \mathrm{O}_{3}$ powders before and after modification in the natural sedimentation

The light transmittance of the dispersion is greatly reduced after grafting polyacrylamide, and the light transmittance of the suspension is less than $10 \%$ after storage for 1 to 3 days; the light transmittance is less than $40 \%$ after 7 days. The light rate is less than $65 \%$ after storage for 15 days. The results show that the dispersion stability of $\mathrm{Al}_{2} \mathrm{O}_{3}$ is obviously improved after modification. The reasons are as follows:

First, carboxylate functional groups were produced due to hydrolysis of polyacrylamide, which increased the 
surface charge of the particles and the charge repulsion between the particles, and the particles are thermodynamically more unstable, so that a stable dispersion system can be formed in water. Second, the branched polyacrylamide is a long-chain polymer, which forms an outer shell on the surface of the particle through the interaction force of the polymer chain, and its steric hindrance prevents agglomeration between the particles; third, the branched polyacrylamide is a water-soluble polymer, which can improve the hydrophilicity and wettability of the particles, and the solvation effect makes the surface energy of the $\mathrm{Al}_{2} \mathrm{O}_{3}$ particles greatly reduced, and can stably exist in an aqueous medium. The mutual adsorption of $\mathrm{Al}_{2} \mathrm{O}_{3}$ particles can be prevented through the combination of static electricity and steric hindrance, and the dispersion stability of $\mathrm{Al}_{2} \mathrm{O}_{3}$ particles in aqueous medium can be improved.

\subsection{Hard disk polishing experiment}

From Fig. 9 a, the surface of unpolished NiP/Al hard disk was rough, and $R$ a was very large $(R a=154 \mathrm{~nm})$. The surface of unpolished NiP/Al hard disk was uneven, had obvious grooves and pits, and had great undulations. From Fig. $9 \mathrm{~b}$, the $\mathrm{Ra}$ of NiP/Al hard disk is significantly reduced $(R a=4.67 \mathrm{~nm})$. The defect pits on the NiP/Al hard disk surface basically disappear, and the depth of the scratches becomes significantly shallower. The viscoelastic polymer coated on the surface of $\mathrm{PAM} / \mathrm{Al}_{2} \mathrm{O}_{3}$ abrasive reduced particle hardness. The polymer acted as a buffer when the abrasive particles hit the hard disk surface, reducing the impact strength of $\mathrm{PAM} / \mathrm{Al}_{2} \mathrm{O}_{3}$ particles on $\mathrm{NiP} / \mathrm{Al}$ hard disk. Therefore, the micro-morphology of NiP/Al hard disk surface was improved, and the Ra was obviously reduced.

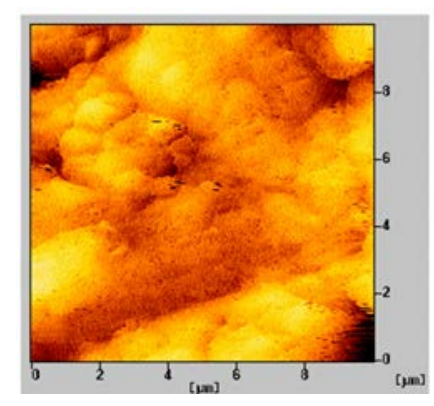

a

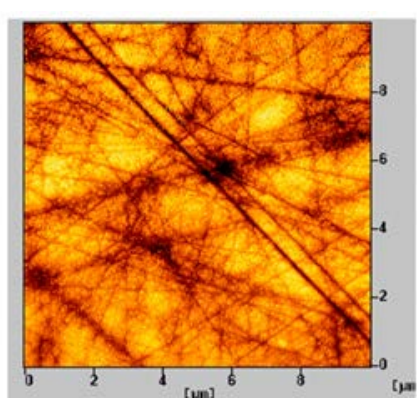

b
Fig. 9. a-AFM images of hard disk surface before polishing; b - after $\mathrm{PAM} / \mathrm{Al}_{2} \mathrm{O}_{3}$ polishing

\section{CONCLUSIONS}

The polyacrylamide $\mathrm{PAM} / \mathrm{Al}_{2} \mathrm{O}_{3}$ composite particles have been successfully synthesised by anchoring the azo initiator on the surface of $\mathrm{Al}_{2} \mathrm{O}_{3}$ particles to initiate the polymerization of acrylamide. The characterization and experimental results indicated that the attained composite abrasive when water-soluble azo initiator was added at $40{ }^{\circ} \mathrm{C}$ showed good dispersion stability in aqueous media with PAM as shell and $\mathrm{Al}_{2} \mathrm{O}_{3}$ as core. This paper can be summarized as follows:
1. XPS and FT-IR spectral analysis showed that polyacrylamide had been grafted onto the surface of $\mathrm{Al}_{2} \mathrm{O}_{3}$ powder by chemical bond;

2. The $\mathrm{D} 50$ of the modified $\mathrm{Al}_{2} \mathrm{O}_{3}$ was reduced, the particle size distribution range is narrowed, and the content of fine particles were obviously increased; the light transmittance was less than $70 \%$ after 15 days of storage; the IEP position of the modified $\mathrm{Al}_{2} \mathrm{O}_{3}$ migrates. After $\mathrm{PAM} / \mathrm{Al}_{2} \mathrm{O}_{3}$ abrasive polished, the surface roughness of $\mathrm{NiP} / \mathrm{Al}$ hard disk surface was obviously reduced;

3. The reason for $\mathrm{PAM} / \mathrm{Al}_{2} \mathrm{O}_{3}$ stably existing in an aqueous medium was that carboxylate functional groups from polyacrylamide hydrolysis increased the surface charge of particles and the charge repulsion between the particles.

\section{REFERENCES}

1. Luo, J., Dornfeld, D.A. Material Removal Mechanism in Chemical Mechanical Polishing: Theory and Modeling IEEE Transactions on Semiconductor Manufacturing 14 (2) 2001: pp. 112-133. https://doi.org/10.1109/66.920723

2. Yang, X.D., Wei, X., Xie, X.Z., Zhuo, C. Development of Theory Model in Chemical Mechanical Polishing Advanced Materials Research 403-408 2011: pp. $767-771$.

https://doi.org/10.4028/www.scientific.net/AMR.403408.767

3. Li, L., Ren, X., Jia, W., Liu, J. Surface Hydrophobic Modification of Ultra-fine Aluminum Silicate by Mechanically Grinding and Heating Applied Surface Science 256 (22) 2010: pp. 6824-6828. https://doi.org/10.1016/j.apsusc.2010.04.095

4. Xin, J., Cai, W., Tichy, J.A. A Fundamental Model Proposed for Material Removal in Chemical-Mechanical Polishing Wear $268(5-6)$ 2010: pp. 837-844. https://doi.org/10.1016/j.wear.2009.12.005

5. Ling, D., Hackett, M.J., Hyeon, T. Surface Ligands in Synthesis, Modification, Sssembly and Biomedical Applications of Nanoparticles Nano Today 9 (4) 2014: pp. $457-477$. https://doi.org/10.1016/j.nantod.2014.06.005

6. Zhi, Q.Y., Shu, L.Y., Zhen, G.Y., Horst, B. Effect of Surface Functional Modification of Nano-Alumina Particles on Thermal and Mechanical Properties of Epoxy Nanocomposites Advanced Composite Materials 20 (5) 2011: pp.487-502. https://doi.org/10.1163/092430411X579104

7. Chen, L., Wang, Y., Zia-ud-Din, Fei, P., Xiong, H., Wang, Z. Enhancing the Performance of Starch-based Wood Adhesive by Silane Coupling Agent (KH570) International Journal of Biological Macromolecules 104 2017: pp. $137-144$. https://doi.org/10.1016/j.ijbiomac.2017.05.182

8. Olding, T., Sayer, M., Barrow, D. Ceramic Sol-Gel Composite Coatings for Electrical Insulation Thin Solid Films 398 2001: pp. 581-586. https://doi.org/10.1016/S0040-6090(01)01322-0

9. Mallakpour, S., Madani, M. The Effect of the Coupling Agents KH550 and KH570 on the Nanostructure and Interfacial Interaction of Zinc Oxide/chiral Poly(amideimide) Nanocomposites Containingl-leucine Amino Acid Moieties Journal of Materials Science 49 (14) 
2014: pp. $5112-5118$.

https://doi.org/10.1007/s10853-014-8220-5

10. Abu-Ilaiwi, Faraj, A., Ahmad, M.B., Ibrahim, N.A., Mohamad, Z., $\quad$ Khairul, Z., $\quad$ Wan, M. Optimized Conditions for the Grafting Reaction of Poly(methyl acrylate) onto Rubberwood Fiber Polymer International 53 (4) 2004: pp. 386-391.

https://doi.org/10.1002/pi.1355

11. Dong, M.J., Zhang, Z.Q., Liu, Q. Influence of Initiator Systems on Gelation Process of Alumina Slurry Journal of Inorganic Materials 23 (2) 2008: pp. 413-416. https://doi.org/10.3724/SP.J.1077.2008.00413

12. Jean-Marie, B., Boutevin, B., Loubet, O. Synthesis of a Perfluorinated Azo Initiator Polymer Bulletin 31 (6) 1993: pp. $673-677$. https://doi.org/10.1007/BF00300126

13. Liu, J.P., Yang, X.M., Wang, X.F., Hu, L. Recent Research Progress on the Synthesis and Application of Water-soluble Azo Initiators Chemical Reagents 33 (4) 2011: pp. 317-320.
https://doi.org/10.3724/SP.J.1105.2011.10085

14. Bouzrati, M., Guillaume, N., Goubard, F. A Novel Class of Photoinitiators for Polymerization Reactions: MetalBased and Metal-Free Photoredox Catalysts with a Thermally Activated Delayed Fluorescence (TADF) Property New Journal of Chemistry $42(10)$ 2018: pp. $8261-8270$. https://doi.org/10.1039/C7NJ04394E

15. Higdon, S.J.U., Weedman, D., Higdon, J.L. First MidInfrared Spectrum of a Faint High-z Galaxy: Observations of CFRS 14.1157 with the Infrared Spectrograph on the Spitzer Space Telescope Astrophysical Journal Supplement 154 (1) 2004: pp. 174-177. https://doi.org/ 10.1086/422218

16. Horkay, F., Hecht, A.M., Rochas, C., Basser, P.J., Geissler, E. Anomalous Small Angle X-ray Scattering Determination of Ion Distribution Around a Polyelectrolyte Biopolymer in Salt Solution The Journal of Chemical Physics 125 (23) 2006: pp. 9041-9048. https://doi.org/10.1063/1.2402921

(c) Ma et al. 2021 Open Access This article is distributed under the terms of the Creative Commons Attribution 4.0 International License (http://creativecommons.org/licenses/by/4.0/), which permits unrestricted use, distribution, and reproduction in any medium, provided you give appropriate credit to the original author(s) and the source, provide a link to the Creative Commons license, and indicate if changes were made. 